\title{
Respiratory Disorder at the End of Surgery for Peritonitis Due to Colorectal Perforation Is a Critical Predictor of Postoperative Sepsis
}

\author{
TAKASHI MOURI ${ }^{1}$, HIDEJIRO KAWAHARA ${ }^{1}$, TOMO MATSUMOTO ${ }^{1}$, \\ KOTA ISHIDA ${ }^{1}$, TAKEYUKI MISAWA ${ }^{1}$ and KATSUHIKO YANAGA ${ }^{2}$ \\ ${ }^{1}$ Department of Surgery, Kashiwa Hospital, Jikei University School of Medicine, Chiba, Japan; \\ ${ }^{2}$ Department of Surgery, Jikei University School of Medicine, Tokyo, Japan
}

\begin{abstract}
Background/Aim: The aim of this study was to identify a critical predictor of postoperative sepsis in patients with peritonitis due to colorectal perforation. Patients and Methods: Between 2009 and 2014, fifty-three patients who underwent emergency surgery for peritonitis due to colorectal perforation in our hospital were examined retrospectively to identify the critical predictor of postoperative sepsis. Between 2016 and 2017, twelve patients with peritonitis due to colorectal perforation were enrolled in a prospective study to validate the critical predictor obtained by the previous retrospective study. Results: Mechanical ventilation for more than two days after surgery seemed to be a critical predictor of postoperative sepsis. In the prospective study, six patients who were withdrawn from mechanical ventilation within one day after surgery did not develop sepsis. Conclusion: Respiratory disorders at the end of surgery for peritonitis due to colorectal perforation seem to be a critical predictor of postoperative sepsis.
\end{abstract}

Emergency surgery is usually required for peritonitis due to colorectal perforation. The morbidity and mortality rates are high due to the performance of emergency surgery itself, incomplete bowel preparation, bacterial proliferation, and contamination $(1,2)$. Several factors, including the age of the patient, preoperative condition, complications, and disease type, have been reported to affect the mortality and

This article is freely accessible online.

Correspondence to: Takashi Mouri, MD, Department of Surgery, Kashiwa Hospital, Jikei University School of Medicine, 163-1 Kashiwashita, Kashiwashi, Chiba 277-8567, Japan. Tel: +81 471641111 Ext. 3421, Fax: +81471633488,e-mail: m-takashi@ mui.biglobe.ne.jp

Key Words: Sepsis, respiratory disorder, critical predictor, peritonitis. the morbidity rates $(3,4)$. Severe postoperative infection often results in serious life-threatening complications, such as sepsis, septic disseminated intravascular coagulation and septic shock (5-7). However, a critical predictor of postoperative sepsis remains unclear. The aim of this study was to identify a critical predictor of postoperative sepsis for patients with peritonitis due to colorectal perforation.

\section{Patients and Methods}

Patients. The Ethics Committee for Biomedical Research at the Jikei Institutional Review Board approved the protocol [30-221 (9242)], and all patients or their family members provided written informed consent for participation. Between 2009 and 2014, fiftythree patients ( 28 male, 25 female) who underwent emergency surgery for peritonitis due to colorectal perforation in our hospital were examined to identify a critical predictor of postoperative sepsis retrospectively. The mean age was 66.5 (range $=26-90$ years) years. The causes of colorectal perforation were constipation in 10 patients $(19 \%)$, strangulation in 8 patients $(15 \%)$, diverticula in 20 patients (38\%), and cancer in 15 patients $(28 \%)$ (Table I).

Between 2016 and 2017, twelve patients ( 7 male, 5 female) who underwent emergency surgery for peritonitis due to colorectal perforation in our hospital were included in a prospective study. The mean age was 64.9 years (range $=42-86$ years). The causes of colorectal perforation were constipation in one patient $(8 \%)$, strangulation in three patients $(25 \%)$, diverticula in 4 patients (33\%), and cancer in 4 patients (33\%) (Table II).

Treatment of patients included in the prospective study. After January 2016, 12 patients who underwent emergency surgery for peritonitis due to colorectal perforation in our hospital were divided into two groups according to postoperative treatment. One group included patients who were withdrawn from mechanical ventilation on the day of surgery or the next day, received only antibiotics for postoperative treatment, and did not perform any intensive treatments. The second group included patients who needed mechanical ventilation for more than two days after the operation and received intensive treatments, such as direct hemoperfusion with a polymyxin B-immobilized fiber column (PMX-DHP) $(8,9)$ or continuous hemodiafiltration (CHDF) $(10,11)$. 
Statistical analysis. Continuous variables are expressed as means and ranges. The Wilcoxon rank-sum test was used to compare continuous variables, and the chi-square test was used to compare categorical data. A $p$-value less than 0.05 indicated significance. All data were analyzed with IBM SPSS Statistics, version 24.0 (IBM Japan, Ltd., Tokyo, Japan).

\section{Results}

Results of the retrospective study

Relationship between treatment after surgery and postoperative hospital stay. Patients whose postoperative hospital stay was 14 days or less received only antibiotics for postoperative treatment. However, patients whose postoperative hospital stay was more than 2 weeks received several treatments including intensive therapy, such as PMXDHP and CHDF (Figure 1).

Comparison of groups with a postoperative hospital stay of 2 weeks or less and longer than 2 weeks (Table III). No significant difference was identified in gender between the two groups. Patients whose postoperative hospital stay was longer than 2 weeks were older and had higher Sequential Organ Failure Assessment (SOFA) scores than patients whose postoperative hospital stay was 2 weeks or less. All seventeen patients whose postoperative hospital stay was 2 weeks or less received only antibiotics for postoperative treatment. They were withdrawn from mechanical ventilation on the day of surgery or the next day. However, all 36 patients who needed mechanical ventilation for more than two days after the operation required longer than 2 weeks postoperative hospital stay and several postoperative treatments.

\section{Results of the prospective study}

Comparison of groups requiring mechanical ventilation for one day and more than two days after surgery (Table IV). Significant differences were found in age, SOFA scores, treatment after surgery, and hospital stay after surgery between the two groups. The postoperative hospital stay of six patients who were withdrawn from mechanical ventilation on the day of the surgery or the next day were fourteen days or less. They received only antibiotics for postoperative treatment and did not require intensive therapy.

\section{Discussion}

Severe peritonitis due to colorectal perforation often results in serious life-threatening complications, such as sepsis, septic disseminated intravascular coagulation and septic shock (5-7). We often perform treatments for these complications (12), which result in increased medical costs. Because there is no critical predictor of postoperative sepsis, it was possible that patients with peritonitis due to colorectal perforation receive unnecessary treatments.
Table I. Clinical features of the patients in the retrospective study.

\begin{tabular}{lc}
\hline Variable & $\mathrm{n}=53$ \\
\hline Age (years) & $66.5(26-90)$ \\
Gender & $28(53)$ \\
Male & $25(47)$ \\
Female & $1.8(0-8)$ \\
SOFA score & \\
Cause of perforation & $10(19)$ \\
Constipation & $8(15)$ \\
Strangulation & $20(38)$ \\
Colon diverticula & $15(28)$ \\
Cancer & $14(26)$ \\
Surgical procedure & $14(26)$ \\
Partial colectomy & $21(40)$ \\
Hartomann's operaiton & $4(8)$ \\
Partial colectomy + ileostomy & \\
Only colostomy or ileostomy &
\end{tabular}

The data are presented as mean (range) or as $\mathrm{n}(\%)$. SOFA: Sequential organ failure assesment.

Table II. Clinical features of patients in the prospective study.

\begin{tabular}{lc}
\hline Variable & $\mathrm{n}=12$ \\
\hline Age (years) & $64.9(42-86)$ \\
Gender & $7(58)$ \\
Male & $5(42)$ \\
Female & $2.8(0-8)$ \\
SOFA score & \\
Cause of perforation & $1(8)$ \\
Constipation & $3(25)$ \\
Strangulation & $4(33)$ \\
Colon diverticula & $4(33)$ \\
Cancer & $3(25)$ \\
Surgical procedrue & $4(33)$ \\
Partial colectomy & $5(42)$ \\
Hartomann's operaiton & $0(0)$ \\
Partial colectomy + ileostomy & \\
Only colostomy or ileostomy &
\end{tabular}

The data are presented as mean (range) or as n (\%). SOFA: Sequential organ failure assesment.

In our retrospective study, we found that patients who were withdrawn from mechanical ventilation on the day of surgery or the next day received only antibiotics for postoperative treatment and did not require any intensive therapy. Their postoperative hospital stay was fourteen days or less. Accordingly, we evaluated the value of respiratory disorders at the end of surgery for peritonitis due to colorectal perforation as a critical predictor of postoperative sepsis in the prospective study. 


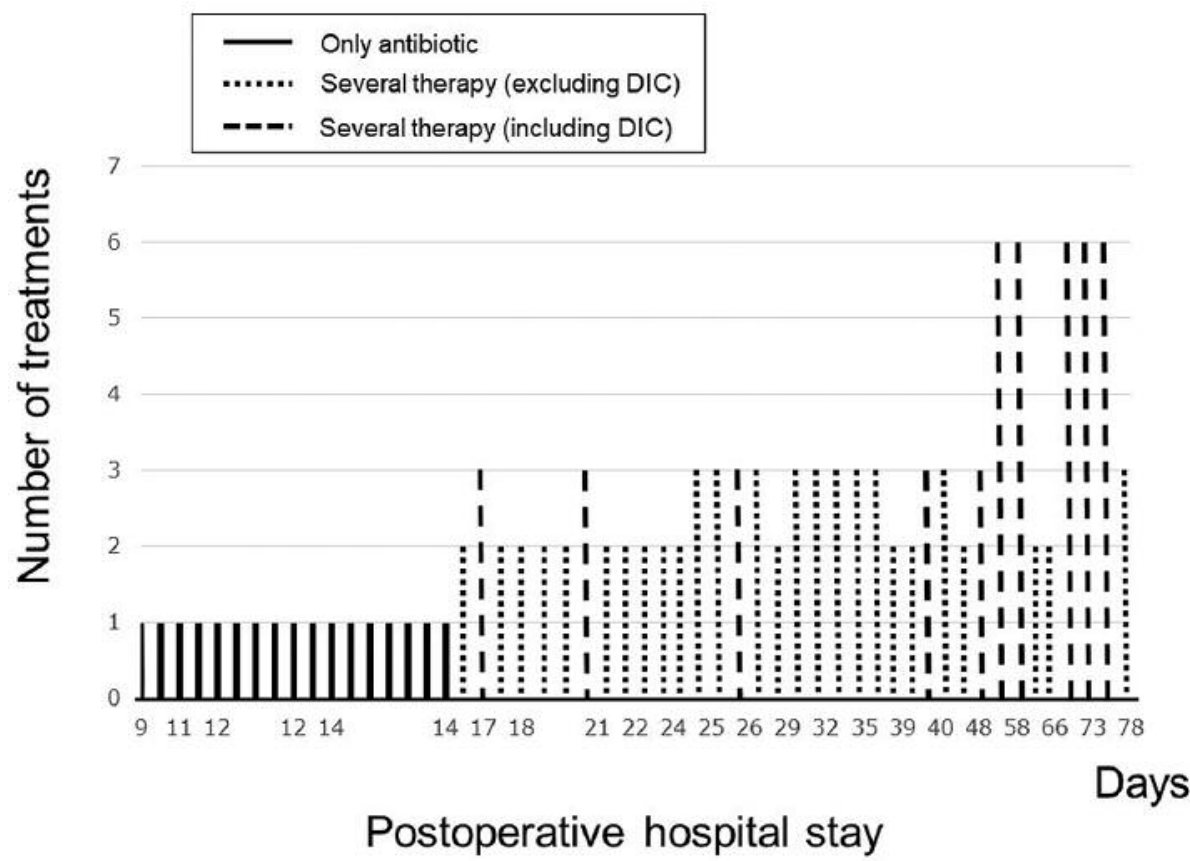

Figure 1. Relationship between treatment after surgery and postoperative hospital stay. Patients whose postoperative hospital stay was within 2 weeks received only antibiotics as postoperative treatment.

Table III. Comparison of groups with a postoperative hospital stay of 2 weeks or less and longer than 2 weeks.

\begin{tabular}{lccc}
\hline Variable & $\begin{array}{c}\text { Within } 2 \\
\text { weeks } \\
(\mathrm{n}=17)\end{array}$ & $\begin{array}{c}\text { Over 2 } \\
\text { weeks } \\
(\mathrm{n}=36)\end{array}$ & $p$-Value \\
& $51.9(26-89)$ & $73.5(50-90)<0.01$ \\
\hline Age (years) & $9(53)$ & $19(53)$ & 1.000 \\
Gender & $8(47)$ & $17(47)$ & \\
Male & $0.05(0-1)$ & $2.3(0-8)$ & $<0.01$ \\
Female & & & $<0.01$ \\
SOFA score & $0(0)$ & $10(28)$ & \\
Cause of perforation & $4(24)$ & $3(8)$ & \\
Constipation & $11(65)$ & $10(28)$ & \\
Strangulation & $2(11)$ & $13(36)$ & \\
Diverticulum & & & $<0.01$ \\
Colon cancer & $11(65)$ & $3(8)$ & \\
Surgical procedure & $2(11)$ & $12(33)$ & \\
Partial colectomy & $4(24)$ & $17(47)$ & \\
Hartmann's opereation & $0(0)$ & $4(12)$ & \\
Partial colectomy + ileostomy & & & \\
Stoma & $17(100)$ & $0(0)$ & \\
Treatment after surgery & $0(0)$ & $36(100)$ & \\
Only antibiotic & & & \\
$\quad$ With other treatment & $17(100)$ & $0(0)$ & \\
The day of extubation & $0(0)$ & $36(100)$ & \\
The day or next day of operation & & & \\
More than 2 days after operation & & & \\
\hline
\end{tabular}

The data are presented as mean (range) or as $\mathrm{n}(\%)$. SOFA: Sequential organ failure assesment.
Table IV. Comparison of groups requiring mechanical ventilation within one day and more than two days after surgery.

\begin{tabular}{|c|c|c|c|}
\hline Variable & $\begin{array}{c}\text { Within one } \\
\text { day } \\
(n=6)\end{array}$ & $\begin{array}{c}\text { More than } \\
2 \text { days } \\
(n=6)\end{array}$ & $p$-Value \\
\hline Age (years) & $59.5(42-86)$ & $70.3(49-81)$ & $<0.01$ \\
\hline \multicolumn{4}{|l|}{ Gender } \\
\hline Male & $5(83)$ & $2(33)$ & 0.242 \\
\hline Female & $1(17)$ & $4(67)$ & \\
\hline SOFA score & $1.2(0-5)$ & $4.5(1-8)$ & $<0.01$ \\
\hline Cause of perforation & & & 0.721 \\
\hline Constipation & $0(0)$ & $1(17)$ & \\
\hline Strangulation & $2(33)$ & $1(17)$ & \\
\hline Diverticulum & $2(33)$ & $2(33)$ & \\
\hline Colon cancer & $2(33)$ & $2(33)$ & \\
\hline Surgical procedure & & & 0.452 \\
\hline Partial colectomy & $1(17)$ & $2(33)$ & \\
\hline Hartmann' s opereation & $3(50)$ & $1(17)$ & \\
\hline Partial colectomy + ileostomy & $2(33)$ & $3(50)$ & \\
\hline Stoma & $0(0)$ & $0(0)$ & \\
\hline Treatment after surgery & & & 0.030 \\
\hline Only antibiotic & $6(100)$ & $2(33)$ & \\
\hline With other treatment & $0(0)$ & $4(67)$ & \\
\hline Hospital stay after surgery & & & 0.030 \\
\hline Within 14 days & $6(100)$ & $2(33)$ & \\
\hline Over 14 days & $0(0)$ & $4(67)$ & \\
\hline
\end{tabular}

The data are presented as mean (range) or as n (\%). SOFA: Sequential organ failure assesment. 
The criteria of withdrawal from mechanical ventilation in our hospital consist of the following three items; 1) Systolic blood pressure higher than $100 \mathrm{mmHg}$ without the use of vasopressors, 2) $\mathrm{PaO}_{2}$ greater than 100 under $40 \%$ oxygenation, 3) Clear consciousness after anesthesia is withdrawn.

In the prospective study, the postoperative hospital stay of six patients who could be withdrawn from mechanical ventilation on the day of surgery or the next day was fourteen days or less. They received only antibiotics for postoperative treatment and did not require intensive therapy. Therefore, patients who could be withdrawn from mechanical ventilation within one day after surgery may not require any intensive treatments because they do not develop sepsis or septic shock. Sepsis-3 is defined as a life-threatening organ dysfunction caused by a dysregulated host response to infection. Organ dysfunction can be identified as an acute change in the total SOFA score of 2 points consequent to infection (13). Respiratory failure was the most common cause of intensive care unit (ICU) admission, followed by acute myocardial ischemia or worsening heart failure, sepsis, gastrointestinal disease, and neurological disease (14). Patients who underwent emergency surgery for peritonitis due to colorectal perforation, did not develop respiratory disorders and required short-term mechanical ventilation after surgery, did not develop sepsis.

In conclusion, respiratory disorders following surgery for peritonitis due to colorectal perforation seems to be a critical predictor of postoperative sepsis; however, a large-scale prospective study is needed to clarify this issue.

\section{Conflicts of Interest}

The Authors declare no conflict of interest regarding this study.

\section{Authors' Contributions}

All Authors performed operations, analyzed the data of patients regarding their clinical features, and have been involved in drafting the manuscript. KY had given final approval of the version to be published. All Authors read and approved the final manuscript.

\section{References}

1 Kwan TL, Lai F, Lam CM, Yuen WC, Wai A, Siu YC, Shung E and Law WL: Population-based information on emergency colorectal surgery and evaluation on effect of operative volume on mortality. World J Surg 32: 2077-2082, 2008. PMID: 18560933. DOI: $10.1007 / \mathrm{s} 00268-008-9632-7$

2 Elshove-Bolk J, Ellensen VS and Baatrup G: Logistics and outcome in urgent and emergency colorectal surgery. Colorectal Dis 12: e255-259,2010. PMID: 19906061. DOI: 10.1111/j.14631318.2009.02120.x

3 Hinchey EJ, Schaal PG and Richards GK: Treatment of perforated diverticular disease of the colon. Adv Surg 12: 85109, 1978. PMID: 735943.

4 Kronborg O: Treatment of perforated sigmoid diverticulitis: a prospective randomized trial. Br J Surg 80: 505-507, 1993. PMID: 8495323.
5 Bielawska B, Day AG, Liberman DA and Hookey LC: Risk factors for early colonoscopic perforation include nongastroenterologist endoscopists: a multivariable analysis. Clin Gastroenterol Hepatol 12: 85-92, 2014. PMID: 23891916. DOI: $10.1016 /$ j.cgh.2013.06.030

6 Tranowski W, Kaminski P, Krzseniak N and Janaszek L: Management of colonoscopic perforations of large bowel. Pol Merkur Le Karski 31: 340-344, 2011. PMID: 22239002.

7 Sagawa T, Kakizaki S, Iizuka H, Onozato Y, Sohara N, Okamura $\mathrm{S}$ and Mori M: Analysis of colonoscopic perforations at a local clinic and a tertiary hospital. World J Gastroentrol 18: 48984904, 2012. PMID: 23002362. DOI: 10.3748/wjg.v18.i35.4898

8 Abe S, Seo Y, Hayashi H, Matsuda K, Usuki J, Azuma A, Kudoh $\mathrm{S}$ and Gemma A: Neutrophil adsorption by polymyxin Bimmobilized fiber column for acute exacerbation in patients with interstitial pneumonia: a pilot study. Blood Purif 29: 321-326, 2010. PMID: 20185904. DOI: 10.1159/000287232

9 Abe S, Seo Y, Hayashi H, Matsuda K, Usuki J, Azuma A, Kudoh $\mathrm{S}$ and Gemma A: Reduction in serum high mobility group box-1 level by polymyxin B-immobilized fiber column in patients with idiopathic pulmonary fibrosis with acute exacerbation. Blood Purif 32: 310-316, 2011. PMID: 21893977. DOI: 10.1159/000330325.

10 Hirasawa $H$, Oda S, Nakamura M, Watanabe E, Shiga $H$ and Matsuda K: Continuous hemodiafiltration with a cytokineadsorbing hemofilter for sepsis. Blood Purif 34: 164-170, 2012. PMID: 23095416. DOI: 10.1159/000342379

11 Shiga H, Hirasawa H, Nishida O, Oda S, Nakamura M, Mashiko K, Matsuda K, Kitamura N, Kikuchi Y and Fuke N: Continuous hemodiafiltration with a cytokine-adsorbing hemofilter in patients with septic shock: a preliminary report. Blood Purif 38 : 211-218, 2014. PMID: 25531978. DOI: 10.1159/000369377

12 Dellinger RP, Levy MM, Rhodes A, Annane D, Gerlach H, Opal SM, Sevransky JE, Sprung CL, Douglas IS, Jaeschke R, Osborn TM, Nunnally ME, Townsend SR, Reinhart K, Kleinpell RM, Angus DC, Deutschman CS, Machado FR, Rubenfeld GD, Webb SA, Beale RJ, Vincent JL and Moreno R; Surviving Sepsis Campaign Guidelines Committee including the Pediatric Subgroup: Surviving sepsis campaign: International guidelines for management of severe sepsis and septic shock: 2012. Crit Care Med 41: 580-637, 2013. PMID: 23353941. DOI: 10.1097/ CCM.0b013e31827e83af

13 Singer M, Deutschman CS, Seymour CW, Shankar-Hari M, Annane D, Bauer M, Bellomo R, Bernard GR, Chiche JD, Coopersmith CM, Hotchkiss RS, Levy MM, Marshall JC, Martin GS, Opal SM, Rubenfeld GD, van der Poll T, Vincent JL and Angus DC: The third international consensus definitions for sepsis and septic shock (Sepsis-3). JAMA 315: 801-810, 2016. PMID: 26903338. DOI: 10.1001/ jama.2016.0287

14 Lin WT, Chen WL, Chao CM and Lai CC: The outcomes and prognostic factors of the patients with unplanned intensive care unit readmissions. Medicine (Baltimore) 97(26): e11124, 2018. PMID: 29952954. DOI: 10.1097/MD.0000000000011124 